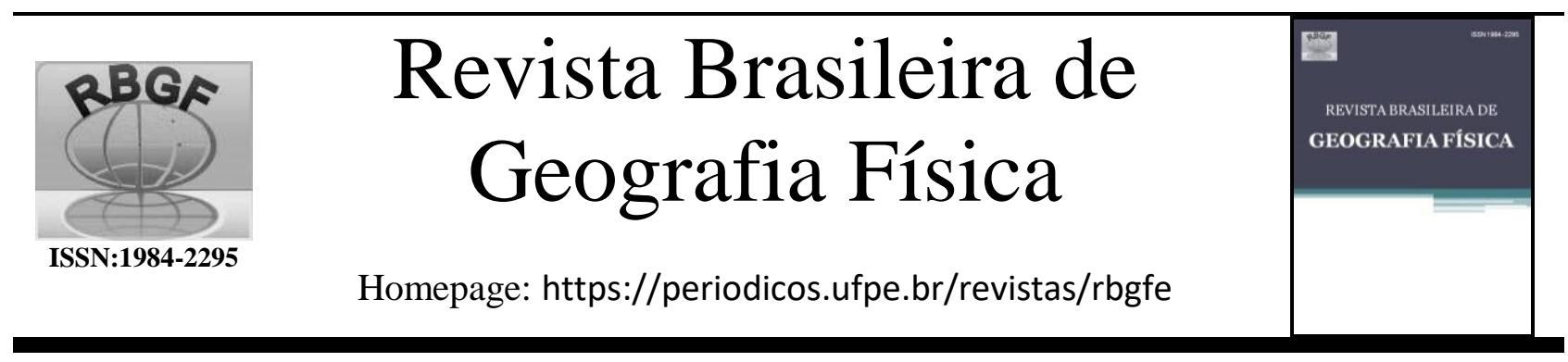

\title{
Análise multitemporal de uso, ocupação e cobertura da terra na zona Leste da cidade de Caxias/Maranhão/Brasil
}

\author{
Patricia Barbosa Pereira ${ }^{1}$, Hikaro Kayo de Brito Nunes ${ }^{2}$, Francisco de Assis da Silva Araújo ${ }^{3}$ \\ ${ }^{1}$ Mestranda em Análise e Planejamento Espacial pelo Instituto Federal do Piauí (IFPI), Praça da Liberdade, 1597, CEP 64.000-040, Centro, Teresina- \\ PI, e-mail: patriiciabarbosaap@ gmail.com (autor correspondente); ${ }^{2}$ Doutorando em Geografia pela Universidade Estadual do Ceará (UECE) e Professor \\ Assistente da Universidade do Estado do Amazonas (UEA), Estrada do Bexiga, 1085, CEP 69470-000, Jerusalém, Tefé-AM, e-mail: \\ hikarobrito@gmail.com; ${ }^{3}$ Doutor em Geografia pela Universidade Estadual Paulista Júlio de Mesquita Filho (UNESP/FCT) e Professor Adjunto da \\ Universidade Estadual do Maranhão (UEMA), Praça Duque de Caxias, s/n, CEP 65.600-000, Morro do Alecrim, Caxias-MA, e-mail: \\ assisaa@gmail.com
}

Artigo recebido em 03/10/2020 e aceito em 19/04/2021

R E S U M O

Com o avanço da quantidade de habitantes no espaço urbano surgem novas formas de modificações no ambiente, e, assim, há o favorecimento da intensificação do processo de antropização, como a supressão da cobertura vegetal, a descaracterização do relevo e danos aos cursos d'água. Frente a isso, o objetivo deste estudo é analisar e quantificar, em escala multitemporal, a dinâmica de uso, ocupação e cobertura da terra da cidade de Caxias/MA com foco na zona Leste por meio de ferramentas obtidas junto ao Sensoriamento Remoto. A metodologia utilizada foi pesquisa bibliográfica, documental e cartográfica. Os mapas temáticos foram confeccionados através da interpretação de imagens obtidas dos satélites Landsat 5 TM (Thematic Mapper) para o ano de 2000 e o Landsat 8 OLI (Operational Land Imager) para 2017, por meio do plugin SCP (Semi-Automatic Classification) do software QGIS 2.18.8. Com os resultados obtidos, constatouse que, a vegetação secundária continuou representando a maior área, apesar da área urbana ter crescido (de 33\% a 35\%). Isso é caraterizado devido à grande área verde no bairro Pai Geraldo e no bairro Baixinha onde está localizada uma fazenda. Diante dos dados e com as etapas de sensoriamento remoto, de campo e de laboratório, este estudo representou uma análise de uso, ocupação e cobertura da terra ocorrida, onde, a partir dela constatou-se as mais diversas atividades desenvolvidas na área, relacionando, ainda, com distintos riscos e impactos socioambientais. Assim, reforça-se a necessidade de novos estudos e a contribuição do sensoriamento remoto para o alcance dos objetivos.

Palavras-chave: cobertura da terra; sensoriamento remoto; zona Leste; Caxias/MA.

\section{Analyze multi-temporal the dynamics of use, land occupation and coverage the on east Zone of the city of Caxias/MA/Maranhão/Brazil}

\begin{abstract}
A B S T R A C T
With the advancement of the amount of people in the urban area there are new forms of changes in environment, and thus there favoring intensifying anthropization process as suppression of vegetation, the relief adulteration and damage to water courses. Faced with this, the general objective of this study was to analyze in multi-temporal scale, the dynamics of use, land occupation and coverage of the city of Caxias/MA with a focus on east Zone East through tools obtained from the Remote Sensing. The methodology used was literature, documentary and cartographic. Thematic maps were made by interpreting images obtained from the Landsat 5 TM (Thematic Mapper) satellites for the year 2000 and the Landsat 8 OLI (Operational Land Imager) for 2017, using the SCP (Semi-Automatic Classification) plugin of the QGIS software 2.18.8. Through the results obtained, it was found that in the zona Leste secondary vegetation continued to represent the largest area, despite the urban area having grown (from $33 \%$ to 35\%). It is characterized because of the large green area in the Pai Geraldo district and Baixinha where it is located a farm. In the face and the remote sensing steps, field and laboratory, this study represents an analysis of use, occupation and land cover occurred in two areas of the city of Caxias/MA where, from there it was found the most diverse activities in the area, also with different risks and environmental impacts. Thus, it reinforces the need for further studies and remote sensing to the achievement of goals. Keywords: land cover; remote sensing; East zone; Caxias/MA.
\end{abstract}




\section{Introdução}

Com o avanço da quantidade de habitantes no espaço urbano, surgem novas formas de modificações no espaço em razão de atenderem as suas necessidades, e, assim, favorecerem a intensificação do processo de antropização, como a supressão da cobertura vegetal, a descaracterização do relevo e danos aos cursos d'água.

Frente aos temas anteriormente citados e baseado no exposto por Araújo, Grigio e Pereira Neto (2019) de que o homem seria o agente principal nas transformações desenvolvidas no planeta Terra, essa preocupação ocasionou $\mathrm{o}$ avanço dos aparatos tecnológicos (como a Cartografia Temática). Dessa maneira, a análise e estudo dos ambientes modificados pela ação antrópica ficou mais rápida e precisa. Assim, neste estudo há possibilidades de reflexões em torno da relação entre o crescimento urbano, econômico e as modificações ambientais com a produção de mapas temáticos sobre o uso e cobertura da terra. Estudos como os de Zhu et al. (2019), Milesi e Churkina (2020) e Figueiredo et al. (2020) auxiliaram, sob distintas escalas (temporal e espacial) no delineamento analítico do presente estudo, uma vez que estes autores constituem-se em importantes análises sobre aplicação do sensoriamento remoto.

De acordo com Cabette e Strohaecker (2015) e Silva et al. (2016) atualmente, o aumento populacional é reflexo das mudanças no contexto global da mudança social. $\mathrm{O}$ processo de urbanização recria novos espaços através das estratégias espaciais de reprodução do capital, notadamente do setor imobiliário e da construção civil. Nas últimas décadas, por exemplo, tais mudanças estão vinculadas com a forte interação estabelecida entre $\mathrm{o}$ ambiente natural e a comunidade, e, neste cenário, insere-se a cidade de Caxias (Maranhão).

Conforme Lei de Divisão de Bairros $\mathrm{n}^{\circ}$ 1.838/2009 a área urbana de Caxias está dividida nas zonas Norte, Sul, Leste e Oeste, compreendendo um total de 35 bairros. Cabe mencionar que em 2015 a Zona Leste teve alteração com a inserção de um novo bairro, a Vila Paraíso. Contudo, para este estudo, foi selecionado a zona Leste, tendo em vista que, ao longo dos últimos anos, ocorreram modificações para a construção de moradias, favorecendo alterações nas formas de uso, ocupação e cobertura das terras urbanas.

De acordo com a Lei supracitada a zona Leste compreende 09 bairros, sendo os seguintes: Baixinha, Bela Vista, Dinir Silva, João Viana, José
Castro, Mutirão, Nova Caxias, Pai Geraldo e Vila Paraíso.

A pesquisa motiva-se pela necessidade de obter informações recentes sobre o processo de uso, ocupação e retirada da cobertura da terra, visto que existe uma carência de trabalhos relacionados com o tema na área de estudo. O trabalho que se segue tem como objetivo analisar e quantificar, em escala multitemporal, a dinâmica de uso, ocupação e cobertura da terra da cidade de Caxias/MA com foco na Zona Leste por meio de ferramentas obtidas junto ao Sensoriamento Remoto.

Sensoriamento Remoto e sua aplicabilidade nos estudos ambientais: síntese teórica

O processo de identificação das alterações causadas na cobertura da terra é obtido por meio do auxílio do Sensoriamento Remoto. Além da utilização das técnicas de Sensoriamento Remoto e as de Geoprocessamento, é necessário um intérprete para identificar as imagens com base nos elementos interpretativos: tonalidade, tamanho, forma, sombra, altura, padrão e localização.

É importante mencionar a importância desse tipo de mapeamento, de modo que o Sensoriamento Remoto aliados ao Sistema de Informação Geográfica se tornaram tecnologias eficazes dos estudos ambientais e de diversos outros ramos da ciência permitindo obter importantes produtos que podem subsidiar o planejamento e gestão do território (Duarte e Silva, 2019; Ferreira, Fonseca e Pereira, 2020).

Nas postulações decorrentes da temática Sensoriamento Remoto é imprescindível discorrer sobre o Geoprocessamento e a introdução sobre Geotecnologias. Sendo necessário, ainda, realizar a menção de um elemento indispensável para esses âmbitos e aos softwares responsáveis pela construção de mapas, o Sistema de Informação Geográfica (SIG), que, conforme Macedo, Mendes e Costa (2018), foram idealizados e desenvolvidos como uma tecnologia voltada a gestão da informação que faz uso de entidades distribuídas geograficamente em grandes extensões territoriais.

Já o Geoprocessamento se configura como um conjunto de técnicas computacionais que opera sobre bases de dados georreferenciados, e estes posteriormente serem transformados em informação e que o conjunto das geotecnologias fazem parte do funcionamento do geoprocessamento (Silva, 1992).

Enquanto que Rosa (2005) expõe que as Geotecnologias são o conjunto de tecnologias para coleta, processamento, análise e oferta de informação com referência geográfica. Dentre as Geotecnologias pode-se destacar: Sistemas de 
Informação Geográfica, Cartografia Digital, Sensoriamento Remoto, Sistema de Posicionamento Global e a Topografia Georeferenciada.

De acordo com os autores supracitados, o Brasil iniciou os investimentos na capacitação de profissionais e no desenvolvimento de infraestrutura que viabilizasse a aplicação das técnicas de Sensoriamento Remoto ao final da década de 1960, com a implantação do Projeto Sensoriamento Remoto no Instituto de Pesquisas Espaciais (INPE).

Para Florenzano (2011) o termo sensoriamento refere-se à obtenção de dados por meio de sensores instalados em plataformas terrestres, aéreas e orbitais, enquanto o termo remoto, que significa distante, é utilizado porque a obtenção é feita à distância, ou seja, sem o contato físico entre o sensor e objetos na superfície terrestre. Dessa forma, para a obtenção de imagens, é necessário a emissão da energia emitida pela superfície terrestre.

Silva (1992) aponta que o campo de pesquisa referente aos estudos ambientais, comporta diversos aspectos, sendo os mais utilizados, possivelmente, a Geoestatística e o Geoprocessamento. De acordo com o autor a aplicação maciça de técnicas de processamento eletrônico de dados, naturalmente associada à captura de dados ambientais referentes a vastas porções da superfície terrestre e, com o auxílio da microcomputação e do processamento gráfico, tornaram-se uma alternativa metodológica para os problemas ambientais.

$\mathrm{O}$ monitoramento sobre as mudanças ocasionadas em face da utilização da cobertura superficial da terra, apresentam variadas perspectivas, e uma delas são os estudos pautados em ações de planejamento dos recursos terrestres (Fisch et al., 2019; Neves et al., 2020).

Os estudos relacionados aos problemas ambientais possuem diversas formas de serem abordados, mas, em particular, o Sensoriamento Remoto e as técnicas de Geoprocessamento são utilizados em grande quantidade para os trabalhos envolvendo a temática ambiental em variadas localizações urbana/rural.

Dentro dessa aplicação, podem ser citados os estudos de Dias (2019) no município de Presidente Prudente em São Paulo, de Moreira et al. (2019) na cidade de Guamá e Nazaré em Belém do Pará e de Oliveira e Aquino (2020) na sub-bacia hidrográfica do rio Gurguéia no Piauí. Portanto, com o surgimento de novas técnicas computacionais, gráfica e geográficas, possibilitam uma ênfase quanto aos estudos referentes sejam na área urbana ou ambiental.

\section{Metodologia}

Quanto aos procedimentos metodológicos adotados no presente estudo, inicialmente houve levantamento e análise de materiais teóricobibliográficos, conceituais, documentais e cartográficos. Essa etapa deu subsídio ao delineamento teórico e auxiliou na delimitação da área de estudo de modo a contribuir na melhor forma de realizar a investigação.

a. Preparação e início da produção cartográfica

A análise foi feita através da interpretação de imagens obtidas dos satélites Landsat 5 TM (Thematic Mapper) para o ano de 2000 e o Landsat 8 OLI (Operational Land Imager) para 2017 disponível no site americano EarthExplorer estando acessível no endereço eletrônico https://earthexplorer.usgs.gov/. Os produtos cartográficos, a quantificação do Índice de Vegetação por Diferença Normalizada (NDVI), e do Geoprocessamento acoplado ao software QGIS que auxiliou nos dados coletados para o estudo e posteriormente na realização dos mapas temáticos.

As séries temporais (2000 e 2017) foram selecionadas através das seguintes justificativas: a) Em 2000, segundo o Censo do IBGE (população residente) no citado ano ocorreu uma redução da população, em comparação com os dados obtidos no Censo anterior (1991); b) Para o ano de 2017, por abranger as mudanças mais recentes no uso e ocupação da cobertura da terra, e, principalmente, os impactos socioambientais ocasionados pela expansão da área urbana na referida zona do estudo.

Os satélites escolhidos foram o Landsat 5 TM para o ano de 2000, devido ser um dos mais utilizados em mapeamento urbano e cobertura vegetal. O outro foi o Landsat 8 OLI para o ano de 2017, a sua escolha se refere à boa qualidade e resolução em suas imagens.

As imagens foram classificadas por meio do plugin Semi-Automatic Classification Plugin (SCP), disponível no software QGIS.

$O$ Índice de Vegetação da Diferença Normalizada (NDVI), dentre os demais índices, é considerado o mais eficiente no que diz respeito a quantificação da vegetação e já proporcionou importantes resultados como obtidos nos estudos de Hutchinson et al. (2015) e Fernandes et al. (2019).

O tratamento das imagens, bem como parte considerável dos procedimentos metodológicos 
foram realizados no Laboratório de Geocartografia do Centro de Estudos Superiores de Caxias (CESC) da Universidade Estadual do Maranhão (UEMA).

\section{b) Produção cartográfica}

Mapa de uso e ocupação da cobertura da terra (base de dados): Foram utilizadas as imagens dos satélites Landsat $5 \mathrm{TM}$ para as imagens do ano de 07 de novembro de 2000 e do Landsat 8 OLI com datação de 06 de novembro de 2017 (órbita 220 e ponto 63). Ambas as imagens foram utilizadas para a confecção do mapa de NDVI. A resolução espacial dos dois satélites correspondem a $30 \mathrm{~m}$, e a escolha das imagens levou em consideração a menor presença de nuvens na área de estudo e em suas proximidades.

Mapa de uso e ocupação da cobertura da terra (processamento e classificação das imagens): Quanto ao processamento das imagens, todas as etapas foram realizadas por meio do software QGIS 2.18.8. Em busca de deixar as imagens em uma composição colorida para melhor serem classificadas, fez-se necessário realizar um Red, Green e Blue (RGB). Nas imagens do satélite Landsat 5 TM foram utilizadas as bandas $5(\mathrm{R}), 4$ (G) e 3 (B), já o Landsat 8 OLI foram as bandas 6 (R), 5 (G) e 4 (B). Além destas, aplicou-se a opção "melhorar contraste" e foi utilizado o "corte de contagem cumulativa" proporcionando melhor qualidade visual dos elementos. Logo após, foi executado um recorte da área de estudo por meio da ferramenta "raster", "extrair" e "recorte".

Para a classificação, utilizou-se o plugin Semi-Automatic Classification (SCP), onde optouse utilizar o algoritmo Maximum Likelihood. De início, se fez necessário realizar a correção atmosférica da imagem para remover quaisquer interferências dos elementos terrestres nos pixels. Os mapeamentos tiveram 5 classes (área urbana, solo exposto, água, vegetação secundária e vegetação antropizada) num total de 15 amostras para cada unidade. Atribuiu-se para cada classe uma cor (área urbana/vermelho, solo exposto/amarelo, vegetação antropizada/verde escuro, vegetação secundária/verde claro e água/azul.

Para a escolha das cores e nome das classes, utilizou-se importantes referencias, tais como: IBGE (2015 e 2017); Pinheiro et al. (2015) e Tamasauskas; Tamasauskas, (2016). Após a coleta das amostras, foi escolhido a classificação que mais se aproximou com as características presentes nas imagens de satélites da área de estudo.

Mapa do Índice de Vegetação da Diferença Normalizada - NDVI (base de dados): As imagens utilizadas pertencem aos mesmos satélites, datas e órbitas/pontos citados na etapa anterior.

Mapa do Índice de Vegetação da Diferença Normalizada - NDVI (processamento e classificação das imagens): Todas as imagens dos respectivos anos foram submetidas a correção atmosférica afim de minimizar quaisquer interferências dos elementos terrestres nos pixels. Para o processamento das imagens do mapa de NDVI, foi utilizado a seguinte fórmula: (NIR RED) / (NIR + RED). Onde Near Infrared (NIR) representa a banda espectral infravermelho próximo e Red (RED) a banda espectral vermelho. Para chegar no objetivo, utilizou-se o software QGIS 2018.8 para gerar a classificação das imagens. Para tanto, a confecção do mapa de NDVI do ano de 2000, foram utilizadas as bandas 3 (RED) e 4 (NEAR INFARED). E no ano de 2017 as bandas $4(R E D)$ e 5 (NEAR INFRARED). Logo após aplicou-se o modo "intervalo igual" num total de 5 classes.

E, para melhorar a visualização da imagem utilizou-se a opção de melhorar contraste do "corte de contagem cumulativa". Vale destacar que, o NDVI possui 3 classes onde os valores variam de vegetação densa (na cor verde), menos densa (na cor bege claro) e a ausência da mesma (na cor vermelho).

\section{c. Acurácia e avaliação dos mapas}

Esta etapa representou a idas em campo para verificar a exatidão das classificações realizadas. Foram realizadas entre o mês de abril de 2019 oito checagens por meio de anotações na caderneta de campo e registro fotográfico, onde estas informações proporcionaram subsídios tanto para ilustração da área de estudo, quanto para os mapas temáticos.

Quanto às imagens utilizadas nos mapas temáticos e corpo do texto para a análise da Zona no ano de 2000, optou-se por utilizar imagens obtidas através do Google Earth. Vale ressaltar que devido apresentar grande quantidade de nuvens as imagens do ano de 2000, fez-se necessário utilizar as imagens de 2004/11. As imagens para o ano de 2017 foi retirada na própria área de estudo. Portanto, a mesma representou a fase de veracidade dos elementos dispostos nos mapas temáticos.

\section{Resultados e discussão}

O processo de ocupação da área (2000 e 2017): subsídios para a investigação

O município de Caxias está localizado no Estado do Maranhão, com coordenadas geográficas $04^{\circ} 53^{\prime} 34^{\prime \prime} \mathrm{S}$ e $43^{\circ} 26^{\prime} 23^{\prime \prime} \mathrm{W}$. Conforme a Lei 
Municipal de Divisão de Bairros n. ${ }^{\circ}$ 1838/2009, a área urbana de Caxias - MA está dividida nas seguintes zonas: Zona Norte, Zona Sul, Zona Leste (figura 1) e Zona Oeste.

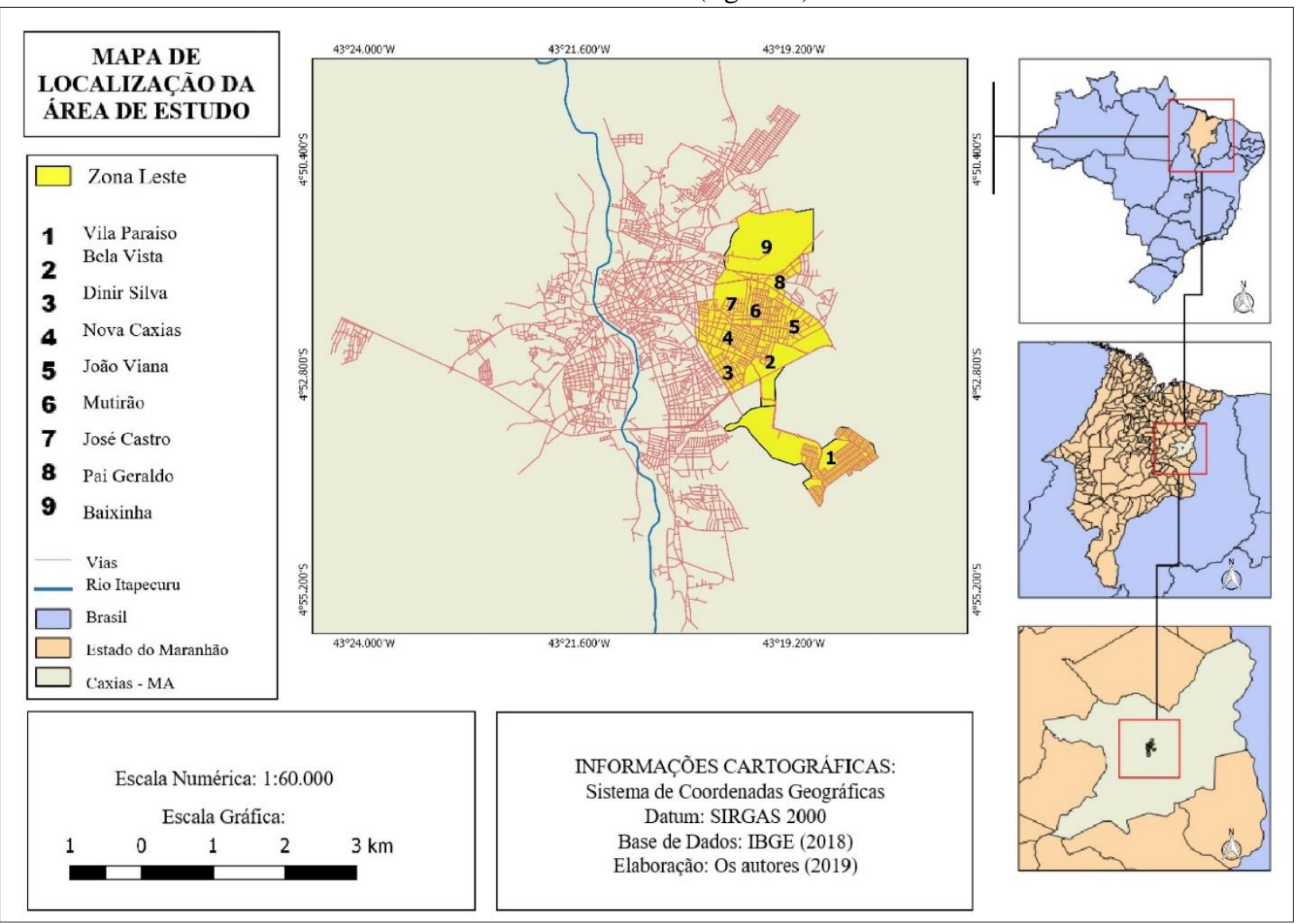

Figura 1: Mapa de localização da área de estudo. Fonte: Os autores (2019)

O processo de ocupação nesta zona foi evidenciado no início da formação da área urbana de Caxias, com a criação do bairro Nova Caxias. Em 2000 se deu a criação do bairro José Castro. Os demais bairros seguiram o zoneamento em 2009, são eles: Baixinha, Bela Vista, Dinir Silva, João Viana, Mutirão e Pai Geraldo. O mais recente dos bairros surgiu em 2015, intitulado de Residencial Vila Paraíso (figura 2).

Como mostra a figura 2, a construção do novo bairro beneficiou várias famílias, de acordo com informações da Secretaria de Finanças, Planejamento e Administração (SEPLAN) onde no mesmo foram construídas três mil unidades habitacionais (informação confirmada em Silva, Lustosa e Veras-dos-Santos, 2016); em contrapartida, a retirada da cobertura vegetal se fez expressiva nessa localidade.
O bairro estava afastado cerca de 5 quilômetros da cidade, e, ao longo dos anos, o vazio urbano foi sendo preenchido pelo resultado de ações acumuladas no tempo, e engendradas por agentes que produzem e consomem espaço. A Zona Leste, caracterizada por casas construídas sem o planejamento urbano, o que favorece problemas comuns em áreas de apropriação inadequada, como por exemplo, o alagamento das ruas e casas devido à falta de espaço para o escoamento de água das chuvas.

Nessa zona estão dispostas uma série de estabelecimentos, como farmácias, supermercado, lojas de confecções, pizzarias, escolas, bares, barbearias, panificadoras, moto peças, igrejas, verdurões, frigoríficos, condomínio, gráfica e shopping center, como mostra a figura 2 . 


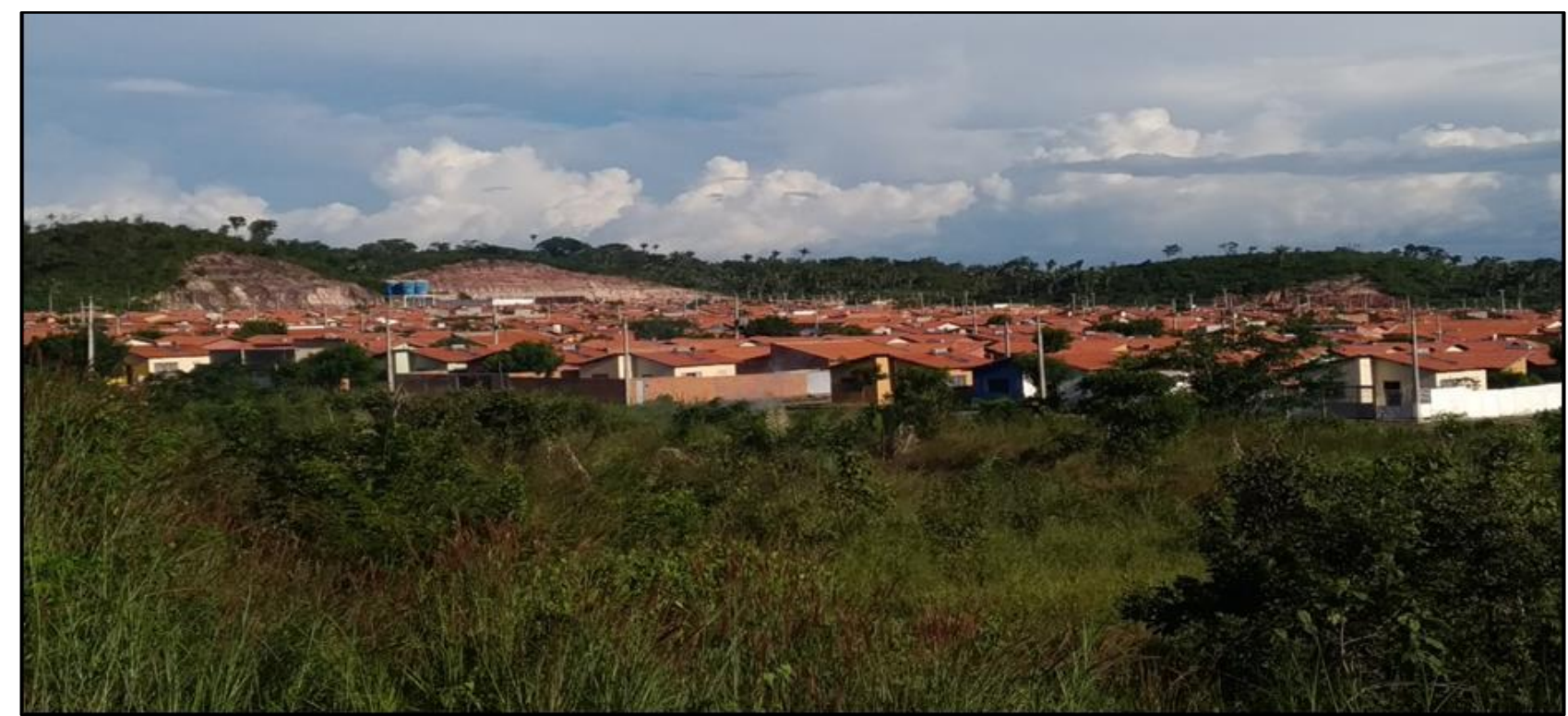

Figura 2: Residencial Vila Paraíso. Fonte: Pesquisa direta (2019)
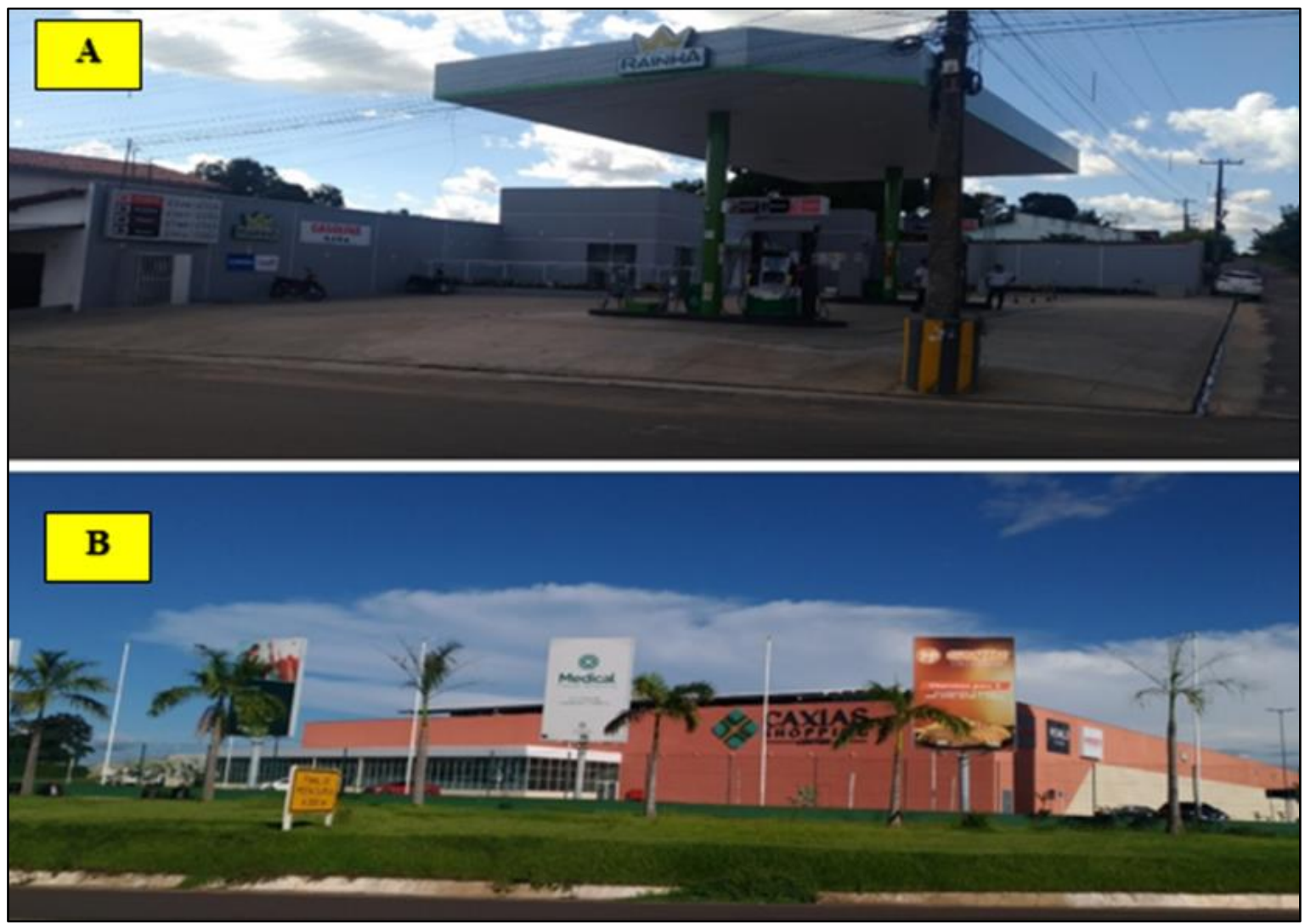

Figura 3: Estabelecimentos comerciais. Em A, posto de gasolina localizado na rua Benjamin Constant no bairro Nova Caxias. Em B, Caxias Shopping Center localizado na rodovia BR-316, bairro Bela Vista. Fonte: Pesquisa direta, 2019.

Como demonstra a figura 3, os estabelecimentos comerciais dessa área são bastante expressivos, principalmente com a construção de um shopping center, em que favoreceu a existência de franquias e proporcionou oportunidades de emprego aos caxienses, além dos surgimentos de vendas dos loteamentos em suas proximidades.

Barros Neto (2015, p.74) afirma que "com o programa do Governo Federal Minha Casa Minha Vida, Caxias ganha o maior projeto de loteamento residencial até então na cidade com a 
construção de 2.000 casas". Nos bairros da referida zona, foram beneficiados com a construção de novas habitações populacionais.

Constata-se habitações de taipa, sobretudo entre os bairros Baixinha e Pai Geraldo, onde é perceptível a falta de infraestrutura nas ruas. Porém, o seu aporte comercial é de grande benefício para a localidade.
Análise multitemporal (2000 e 2017) de uso, ocupação e cobertura da terra

A figura 4, apresenta o resultado da classificação supervisionada de uso e ocupação da cobertura da terra na Zona Leste no ano de 2000.

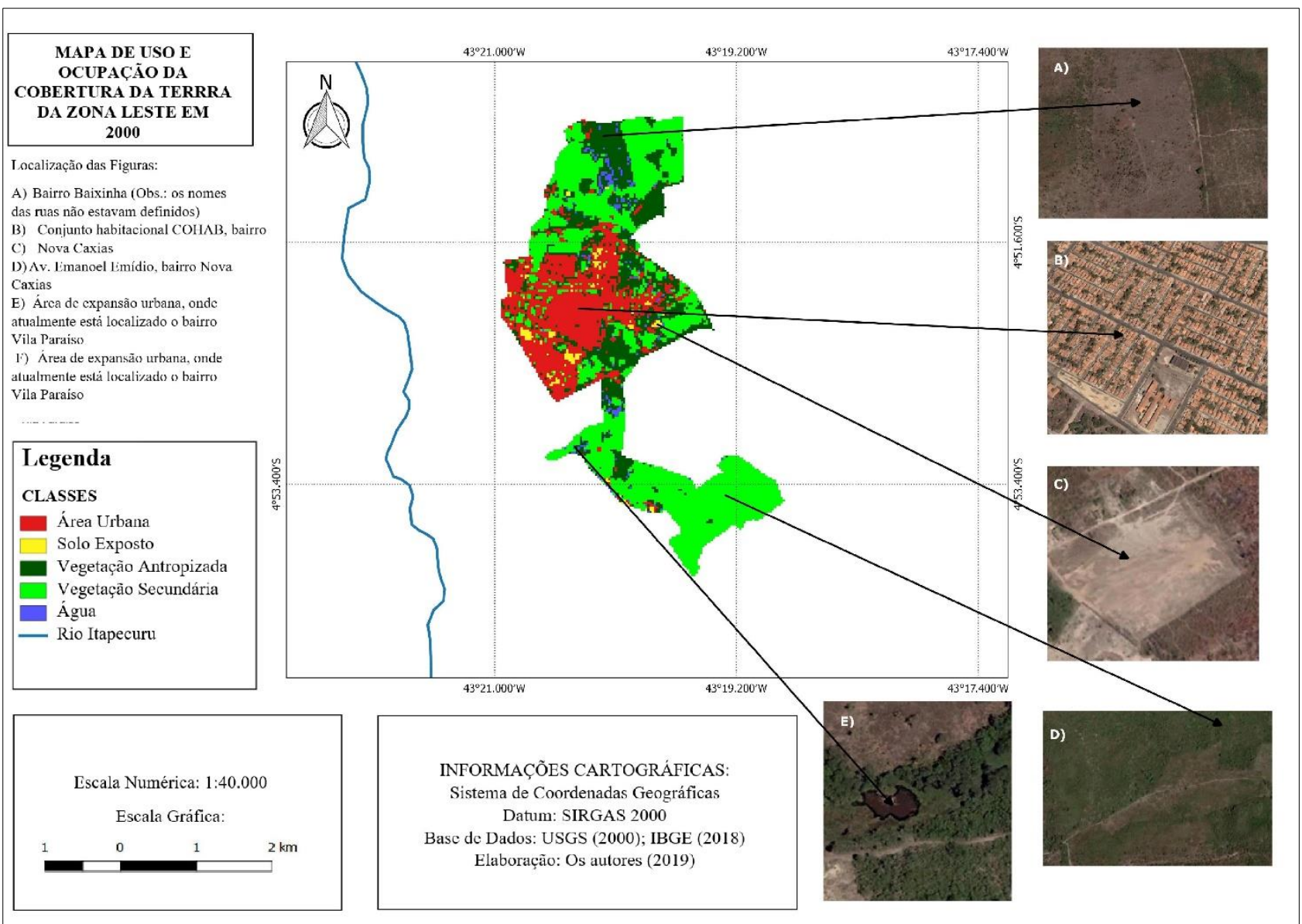

Figura 4: Mapa de uso, ocupação e cobertura da terra na Zona Leste em 2000. Fonte: Os autores, 2019

A figura 4 representa os resultados obtidos a partir da classificação supervisionada de uso, ocupação e cobertura da terra realizada na Zona Leste no ano de 2000. As cores que representam maior área territorial são o verde claro que corresponde a vegetação secundária e o vermelho que ilustra a área urbana. O gráfico 1 esboça a quantificação obtida através da classificação supervisionada. 


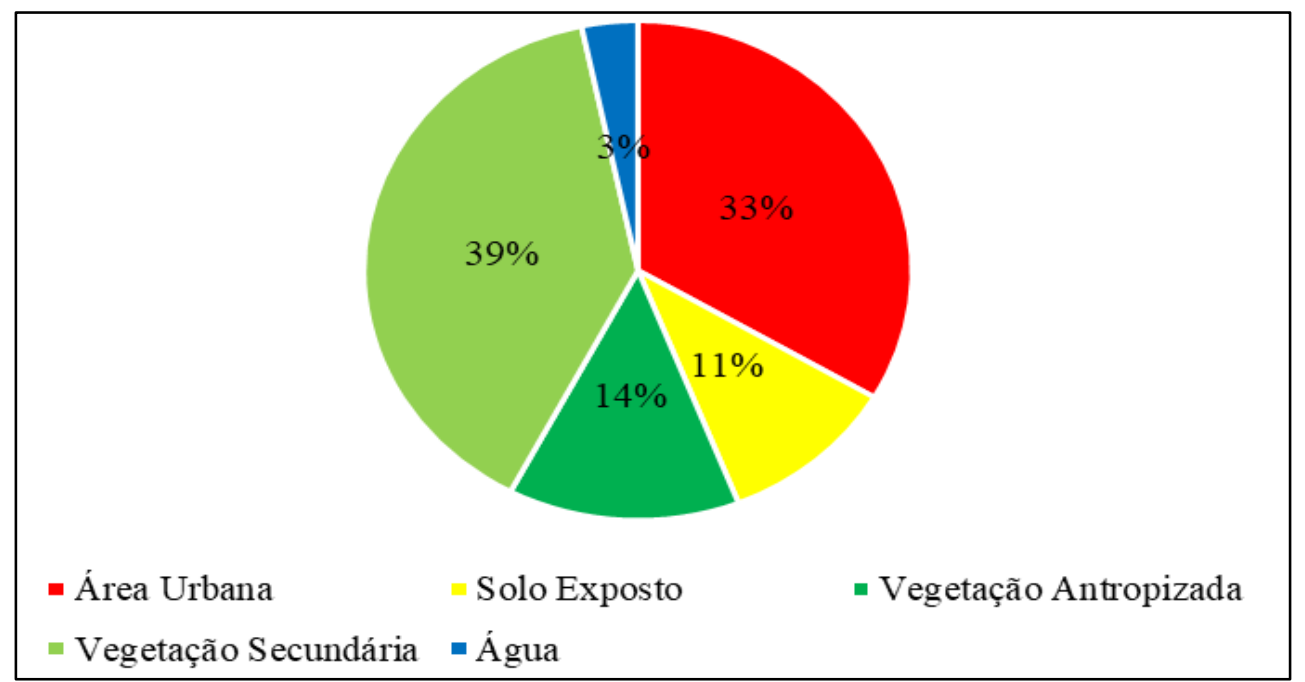

Gráfico 1: Quantificação da Zona Leste em 2000. Fonte: Pesquisa direta, 2019

Averígua-se que a classe com maior percentual é a vegetação secundária, em seguida a área urbana, a vegetação antropizada, o solo exposto e a água. O maior percentual da quantificação, se refere a grande quantidade de vegetação com menos atuação antrópica, sobretudo em áreas de bairros que iam se firmar em 2009.

O percentual da área urbana de $33 \%$ é bastante significativa, valendo explanar que os primeiros bairros da cidade estavam localizado na Zona Leste. É importante visualizar estas características, para tanto, a figura 5 mostra a representação de ganha e/ou perda de vegetação, como também identificado nas análises de Zhu et al. (2019) e Milesi e Churkina (2020) em suas respectivas áreas de estudo.

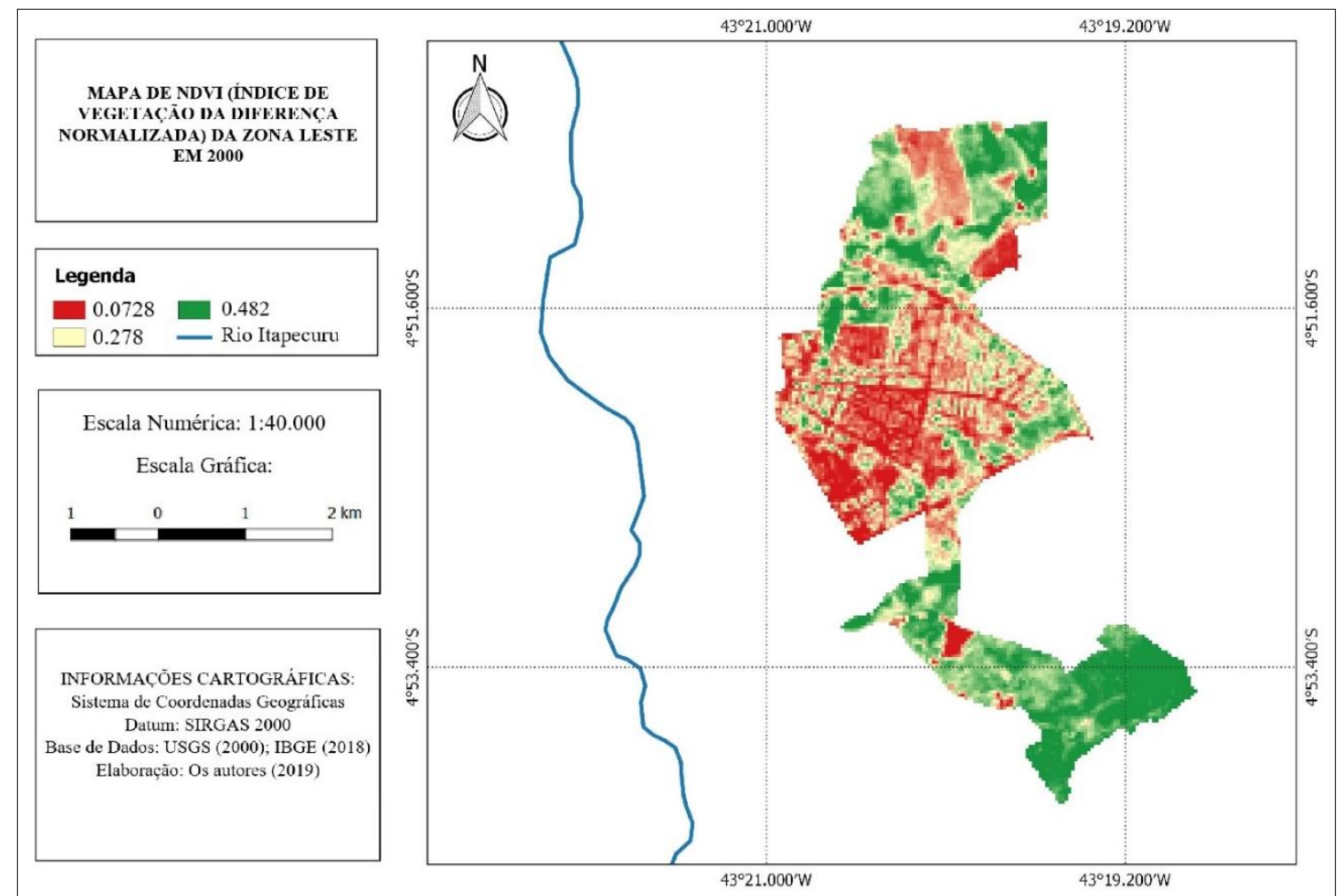

Figura 5: Mapa do Índice de Vegetação da Diferença Normalizada (NDVI) em 2000. Fonte: Os autores, 2019

Com base na figura 5 evidencia-se a vegetação densa, menos densa e ausência da vegetação. De acordo com a mesma, a vegetação densa apresenta os maiores números, em seguida a menos densa. A figura 6 representa algumas da alterações ocorridas. 
A figura 6A mostra um local que no ano de 2000 era uma área de expansão urbana, apenas em 2015 se tornou um bairro. Antes da inserção do bairro, a localidade apresentava vegetação densa e menos densa. Em 6B, representa o bairro Mutirão com significativa quantidade de habitações.

$\mathrm{O}$ que se percebe atualmente na área da figura A é a grande quantidade de casas e solo exposto, já que na área foi construída um residencial com mais de 1.000 residências, e ainda está em processo de construção de outro residencial, mas esse de cunho privado. Percebe-se então a retirada da cobertura vegetal para atingir os fins da sociedade.

A figura 7 ilustra as modificações ocorridas em 2017, se fez necessário para melhor identificar as alterações ocorridas em um dado período no espaço geográfico.

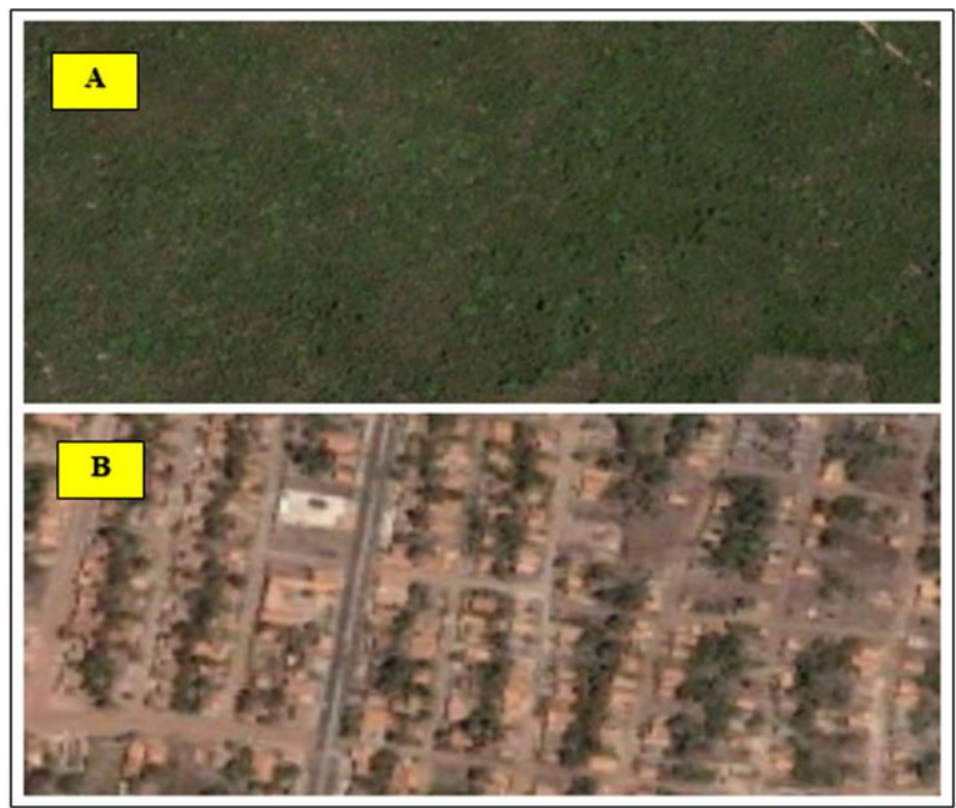

Figura 6: Em A, bairro Vila Paraíso. Em B, bairro Mutirão.. Fonte: Google Earth, 2004

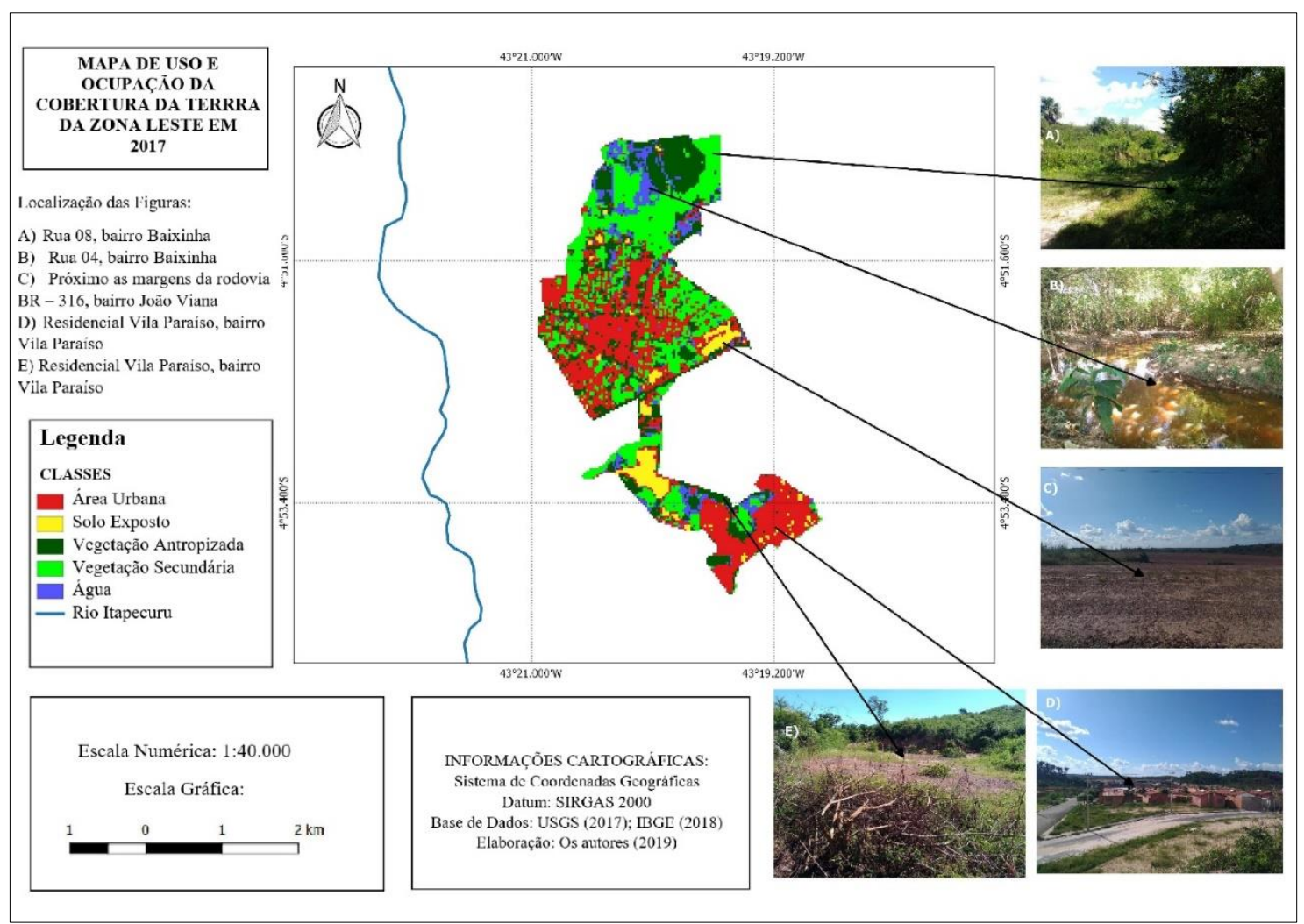

Figura 7: Mapa de uso, ocupação e cobertura da terra em 2017. Fonte: Os autores, 2019 
De acordo com a figura 7, a classificação supervisionada indica uma grande quantidade de vegetação secundária, em seguida a área urbana.
Para constatar de forma quantitativa as classes, o gráfico 2 apresenta as quantificações das mesmas.

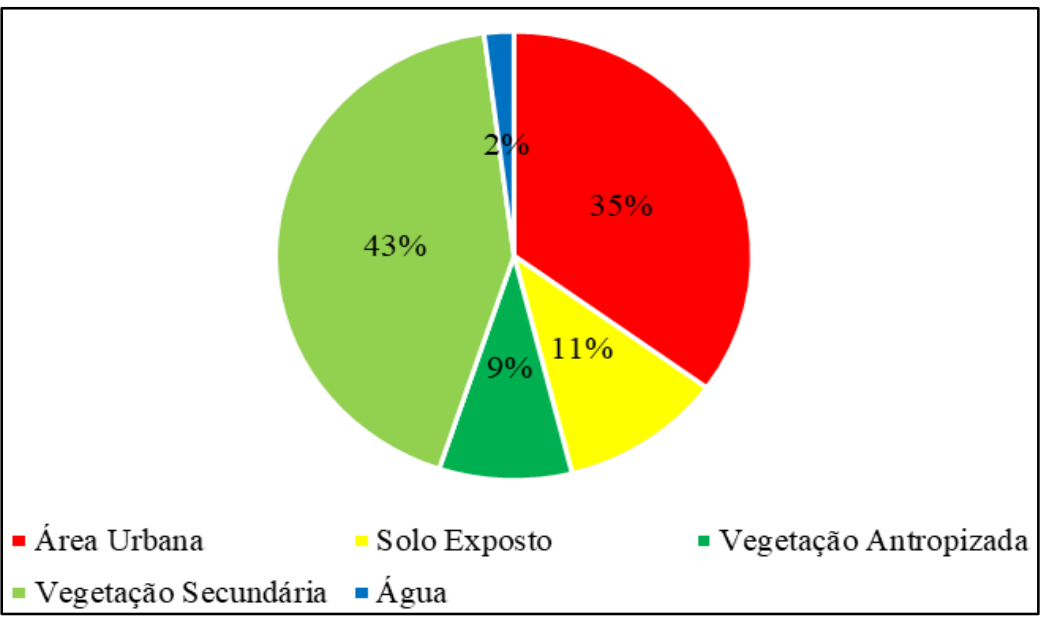

Gráfico 2: Quantificação das classes da Zona Leste em 2017. Fonte: Pesquisa direta, 2019

O gráfico 2 mostra o percentual obtido através da classificação supervisionada de uso, ocupação e cobertura da terra. Onde a vegetação secundária permaneceu abrangendo a maior parte da zona, em seguida da área urbana. O solo exposto permaneceu com sua quantidade, já a vegetação antropizada ocorreu decréscimo e a classe de água.

Salienta Florenzano (2011) que os ambientes construídos ou transformados pela ação do homem ocupam cada vez mais áreas da superfície terrestre. $\mathrm{O}$ homem transforma os espaços em razão de atenderem suas necessidades e as fazem por meio da derrubada das matas, construção de estradas e etc. As alterações ocorridas no espaço urbano, reflete grandemente na cobertura vegetal e até nos corpos d'água.

Para tanto, é imprescindível verificar as modificações ocorridas quanto a vegetação densa, vegetação menos densa e ausência de vegetação da área, conforme mostra a figura 8 .

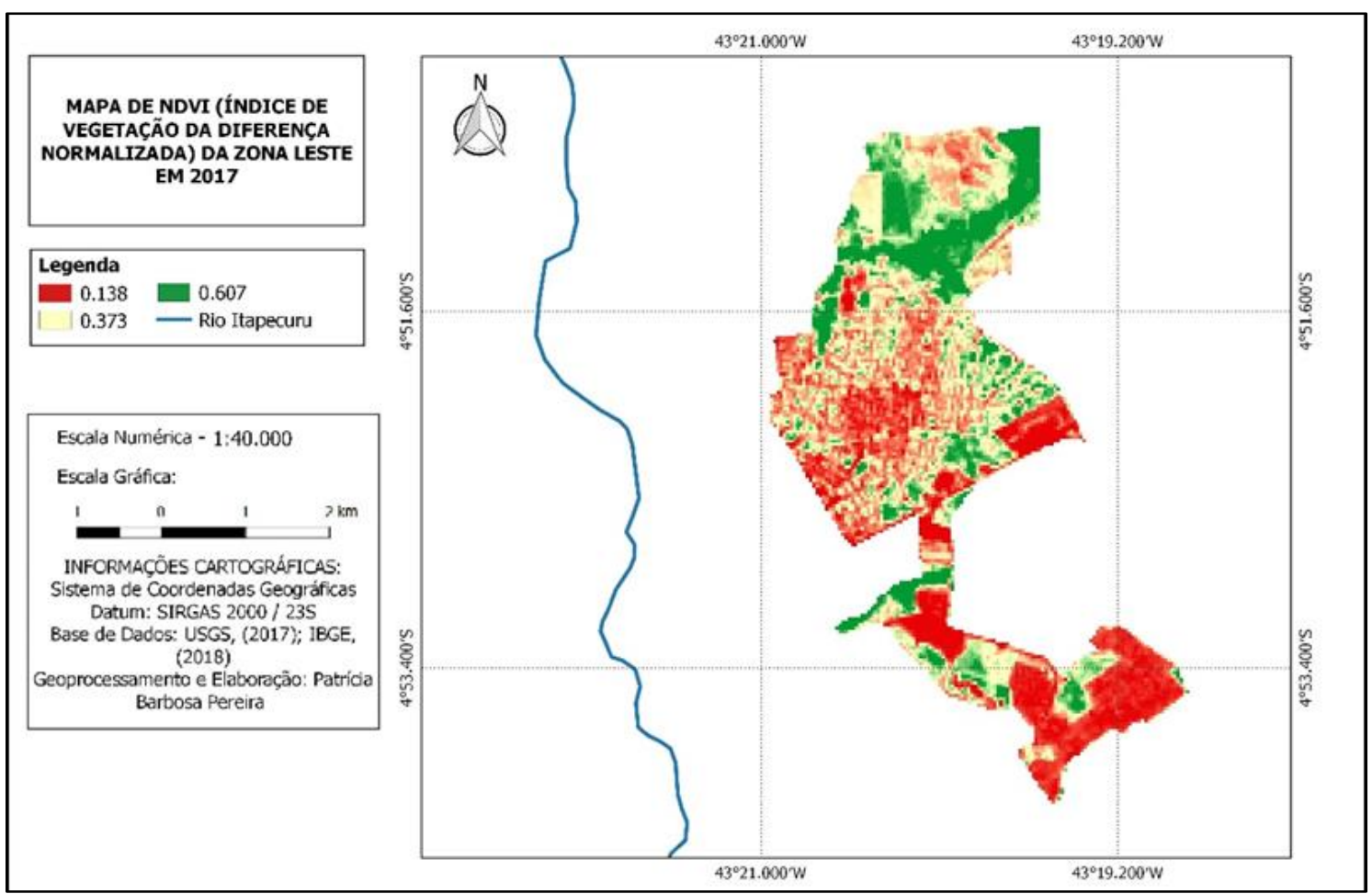

Figura 8: Mapa de uso, ocupação e cobertura da terra em 2017. Fonte: Os autores, 2019 
Com base na figura 8 , mostrando o NDVI da vegetação, verifica-se que, a vegetação densa e menos densa teve acréscimo, mesmo com o crescimento da área urbana. Isso se evidencia por conta da grande vegetação ainda existente sobretudo nos bairros Baixinha e Pai Geraldo, conforme a figura 9 .
No mapa de NDVI do ano de 2017 (figura 8) verificou-se grande área com vegetação onde é atualmente o residencial Vila Paraíso, porém, a vegetação "preservada" cresceu, principalmente na área onde está localizada uma Fazenda no bairro Baixinha.

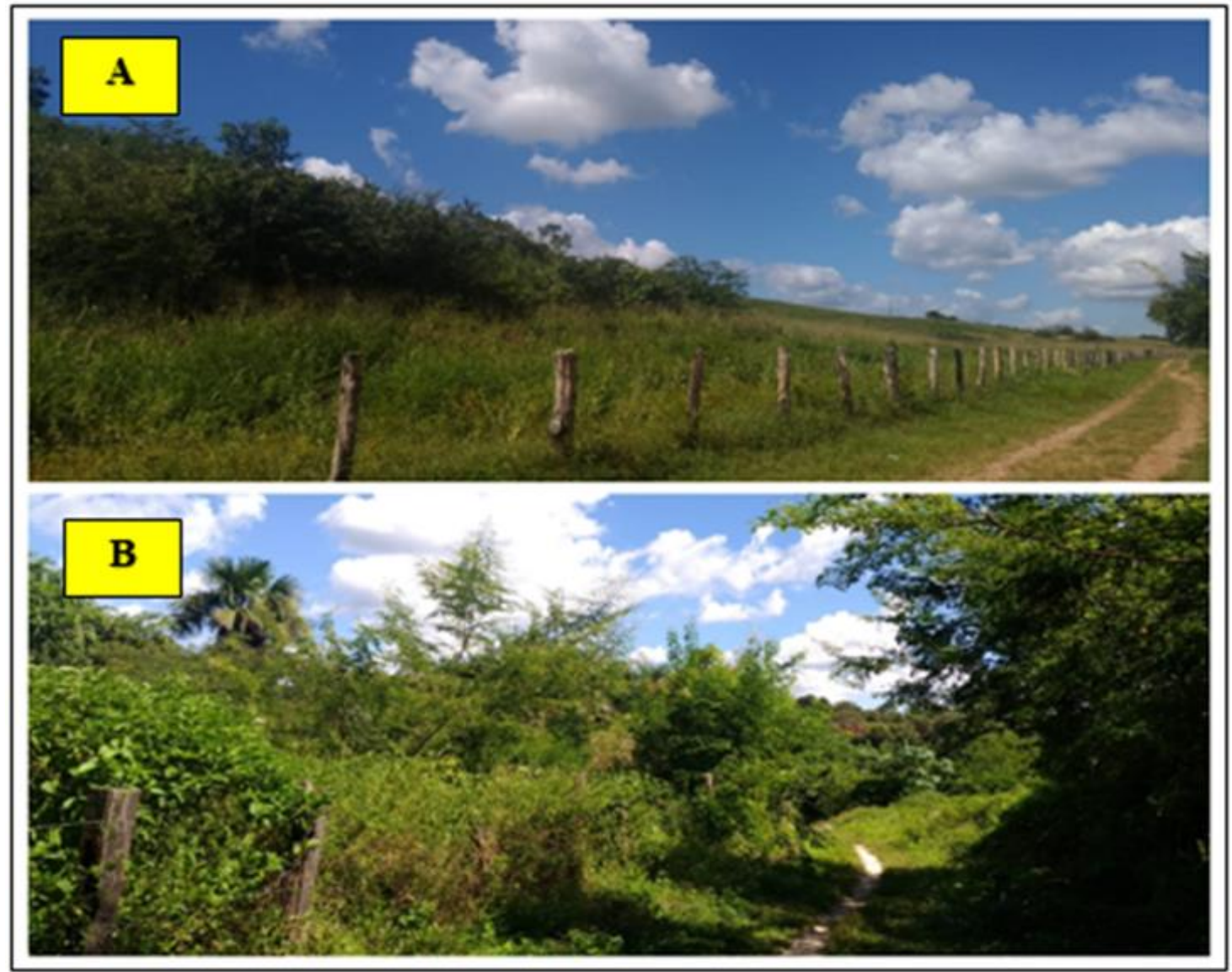

Figura 9: Em A e B, bairro Baixinha. Fonte: Pesquisa direta, 2019

Em A, localizado em terrenos de uma fazenda representando uma área com bastante vegetação. Em B, uma área próxima ao Riacho São José, onde a área vegetacional tende a ser mais densa.

A nível de comparação entre a análise multitemporal da Zona Leste entre 2000 e 2017, foi comprovado por meio dos mapeamentos e quantificações, o crescimento da área urbana. Com base nos estudos de Couto, Garcia e Silva (2018) eles identificaram que os efeitos adversos do processo de urbanização acelerado e sem planejamento, tem ocasionado sérios problemas de ordem ambiental.

Complementando o postulado anterior, Silva et al. (2016) ao tratar do tema de análise espaço-temporal de um determinado município, referenciou que as alterações ocorridas em uma dada escala temporal traz consigo diversas alterações, além de que algumas destas, tomando como exemplo principal a retirada da cobertura vegetacional, traz uma série de problemas ambientais.

Outras alterações identificadas através dos mapeamentos foram as classes de vegetação antropizada que diminuiu ao longo dos 17 anos, seguida da classe de água. No que diz respeito aos corpos d'águas, isso se caracteriza devido a utilização deles para uso próprio. $\mathrm{O}$ solo exposto permaneceu com a sua porcentagem, mas esta classe é bastante identificada no bairro Vila Paraíso, onde foi retirado a cobertura vegetal para a construção de um residencial privado.

A Zona Leste, ao contrário da outra zona, com base na quantificação e no mapa de NDVI, a vegetação secundária cresceu o seu percentual. Dessa forma, constata-se que, apesar da inserção de 
um novo bairro, boa parte da vegetação secundária ainda permanece em bom estado de conservação.

A classificação supervisionada bem como o mapa de NDVI e os gráficos de quantificações serviram de bastante valia para representar visualmente e quantitativamente os resultados obtidos para esta análise multitemporal, haja vista que o mapeamento foi comprovado por meio das idas a campo.

\section{Conclusão}

Em concordância com os resultados obtidos neste estudo, constata-se que o processo de ocupação de ambas as zonas ocorreu de forma desordenada. Isso acarreta em diversos problemas aos moradores, como moradias situadas em encostas e próximas aos corpos d'águas. Sabe-se que, no período chuvoso o transtorno multiplica, visto que, as chances de deslizamentos e alagamentos nas residências se tornam mais propício.

A Zona Leste na análise de 2000, verificou-se que a vegetação secundária também apresentava maior porcentagem em relação a área urbana. Dessa forma, a área de maior percentual refere-se a grande quantidade de vegetação com menos atuação antrópica, sobretudo em áreas de bairros que iam se firmar em 2009.

Em 2017, a vegetação secundária continuou representando a maior área, apesar da área urbana ter crescido. Isso é caraterizado devido à grande área verde no bairro Pai Geraldo e no bairro Baixinha onde está localizado uma fazenda.

Os impactos socioambientais ocorridos nas áreas são dos mais diversos, predominando a grande retirada de vegetação para a construção de moradias, mesmo em locais impróprios (próximo a encostas), despejos de dejetos domésticos em áreas onde estão localizadas uma vegetação preservada. Além disso, a poluição dos efluentes nos corpos riachos, o que acarreta em perdas de sua flora e fauna, e, principalmente, o assoreamento no leito e nas margens.

Destaca-se ainda, diversos estudos no território brasileiro com a temática dos impactos antrópicos utilizando o Sensoriamento Remoto e o Geoprocessamento, ratificando, assim, a eficiência destas técnicas de pesquisas, como: entre os estados de Mato Grosso e Pará (Rocha e Santos, 2019); em São Paulo (Rodrigues et al., 2019); em Goiás (Ribeiro; Faria e Cezare, 2019) e em Recife/Pernambuco (Oliveira; Candeias e Tavares Júnior, 2019).

\section{Agradecimentos}

Os autores da pesquisa agradecem ao Laboratório de Geocartografia do Centro de Estudos Superiores de Caxias (CESC) da Universidade Estadual do Maranhão (UEMA) por toda estrutura utilizada.

\section{Referências}

Araújo, J.P.R., Grigio, A.M., Pereira Neto, M.C. 2019. Análise multitemporal de uso e ocupação do solo (1977-2018) e identificação de impactos ambientais negativos no município de Assú/RN. Revista Brasileira de Geografia Física, 12, 1538-1553. Disponível: https://periodicos.ufpe.br/revistas/rbgfe/article/ view/239945. Acesso: 03 mar. 2020

Barros Neto, E. 2015. Desenvolvimento Urbano. In: Sousa, I. G.; Meneses, R. L. de; Viana, J. M. (Org.). Cartografia Invisíveis. Academia Caxiense de Letras.

Caxias. Lei de Divisão de Bairros $n^{\circ} 1.838 / 2009$, de 31 de dezembro de 2009. 2010. Prefeitura Municipal de Caxias: dispõe sobre a criação e a divisão dos bairros da cidade de Caxias - MA, com estabelecimento de novos limites, e dá outras providências.

Cabette, A., Strohaecker, T. M. 2015. A dinâmica demográfica e a produção do espaço urbano em Porto Alegre, Brasil. Cadernos Metrópole 17, 481-501. Disponível: http://www.scielo.br/pdf/cm/v17n34/22369996-cm-17-34-0481.pdf. Acesso: 03 mar. 2020.

Couto, R., Garcia; K. J., Silva, M. L.2018. Conflitos de uso e ocupação do solo nas áreas de preservação permanente do Município de Inconfidentes - MG. 11, 2244-2259. Disponível:https://periodicos.ufpe.br/revistas/r bgfe/article/view/236867. Acesso: 03 mar. 2020.

Duarte, M. L., Silva, T. A. 2019. Avaliação do desempenho de três algoritmos na classificação de uso do solo a partir de geotecnologias gratuitas. REA - Revista de estudos ambientais (Online), 21, 6-16. Disponível:https://proxy.furb.br/ojs/index.php/ rea/article/view/7427. Acesso: 03 mar. 2020.

Fernandes, P. J. F., Vicens, R. S., Girão, R., Furtado, L. F. A. 2019. Análise de tendências de índice de vegetação (IV) MODIS na bacia do Paraíba do Sul. Revista Brasileira de Geografia Física,12, 1600-1617. Disponível:https://periodicos.ufpe.br/revistas/r bgfe/article/view/238192. Acesso: 03 mar. 2020. 
Ferreira, A. B. R., Fonseca, B. M., Pereira, G. 2020. Compartimentação do relevo baseada em parâmetros morfométricos: uma análise da região do extremo oeste da Bahia. Caderno de Geografia, 30, 236-251. Disponível: http://periodicos.pucminas.br/index.php/geogra fia/article/view/21641/16404. Acesso: 03 mar. 2020.

Figueiredo, H.R.; Dalmas, F.B.; Loubet, L.F.; Paranhos Filho, A.C. 2020. Análise de impactos ambientais através de geotecnologias em área úmida do município de Bonito - MS, Brasil. Enciclopédia Biosfera, v.17, n.31, 13-26. Disponível em: http://www.conhecer.org.br/enciclop/2020A/an alise\%20dos\%20impactos.pdf.http://www.con hecer.org.br/enciclop/2020A/analise $\% 20 \mathrm{dos} \%$ 20impactos.pdf

Fisch, F., Branco, J. O., Port, D., Menezes, J.T., 2019. Variação espaço-temporal (1938-2013) do uso e ocupação da terra na região do Saco da Fazenda, Itajaí-SC. Geosul, 34, 430-445. Disponível:

https://periodicos.ufsc.br/index.php/geosul/arti cle/view/2177-5230.2019v34n70p430/38528.

Acesso em: 21 abr. 2021.

Florenzano, T. G. 2011. Iniciação em sensoriamento. Oficina de Textos.

QGIS, Development Team. 2016. QGIS Geographic Information System. Open Source Geospatial Foundation.

Hutchinson, J. M. S., Jacquin, A., Hutchinson, S. L., Verbesselt, J. 2015. Monitoring vegetation change and dynamics on U.S. Army training lands using satellite image time series analysis. Journal of Environmental Management, 150, 355-366.

Disponível: https://research.wur.nl/en/publications/monitor ing-vegetation-change-and-dynamics-on-usarmy-training-lan. Acesso: 03 mar. 2020.

IBGE. Instituto Brasileiro de Geografia e Estatística, 1991. Censo Demográfico de 1991. Rio de Janeiro. 2000. Censo Demográfico de 2000. Rio de Janeiro. 2015. Mudanças na Cobertura e Uso da Terra 2000 - 2010 - 2012. Rio de Janeiro: Diretoria de Geociências. IBGE.

2017. Monitoramento da cobertura e uso da terra do Brasil 2000 - 2010 - 2012 - 2014. Rio de Janeiro: Diretoria de Geociências. IBGE. Macedo, R. R., Mendes, R. L. R., Costa, T. 2018. Sistema de informação geográfica (sig) aplicado a gestão de recursos naturais. Atlas do aproveitamento de água da chuva nas ilhas de belém - iniciativas, demandas e potencialidades. Revista Geo UERJ, 1-38. Disponível:https://www.epublicacoes.uerj.br/in dex.php/geouerj/article/download/29876/2526 2. Acesso: 03 mar. 2020.

Milesi, C.; Churkina, G. 2020. Measuring and Monitoring Urban Impacts on Climate Change from Space. Remote Sensing. 12, 1-25. Disponível em: https://www.mdpi.com/20724292/12/21/3494. Acesso: 21 abr. 2021.

Moreira, F. S. A., Dias, G. F.M., Vitorino, M. I., Silva, J. C. C., Holanda, B. S. 2019. Caracterização da urbanização e seu impacto nas variáveis socioambientais: Guamá e Nazaré em Belém, Pará. Revista InterEspaço, 5,0127.Disponível:http://www.periodicoseletronico s.ufma.br/index.php/interespaco/article/view/1 1775. Acesso: 03 mar. 2020.

Neves, A. K., Körting, T. S., Fonseca, L. M. G., Escada, M. I. S., 2020. Assessment of TerraClass and MapBiomas data on legend and map agreement for the Brazilian Amazon biome. Acta Amazonica, 50 (2): 170 - 182. Disponível:

https://www.scielo.br/pdf/aa/v50n2/00445967-aa-1809-4392201900981.pdf. Acesso em: 21 abr. 2021.

Oliveira, C. B. S., Candeias, A. L B., Tavares Júnior, J. R. 2019. Utilização de índices físicos a partir de imagens OLI - TIRS para o mapeamento de uso e cobertura da terra no entorno do aeroporto internacional do Recife/Guararapes - Gilberto Freire. Revista Brasileira de Geografia Física,12, 1039-1053. Disponível:

https://periodicos.ufpe.br/revistas/rbgfe/article/ view/237236. Acesso: 04 jan. 2020.

Oliveira, L. N., Aquino, C. M. S. 2020. Dinâmica temporal do uso e cobertura da terra na fronteira agrícola do matopiba: análise na sub-bacia hidrográfica do rio Gurguéia-Piauí. Revista Equador (UFPI), 9, 317 - 333. Disponível: https://revistas.ufpi.br/index.php/equador/articl e/view/9461. Acesso: 03 mar. 2020.

Pinheiro, L.C. S.J., Gomes, R.A.T., Carvalho Júnior, O.A., Guimarães, R.F., Oliveira, S.N. 2015. Mudanças do uso da terra e fragmentação da paisagem no município de Correntina (BA) durante 1988-2008. Revista Ra'e Ga, 35, 169198.

Disponível: https://revistas.ufpr.br/raega/article/view/3994 1/27802. Acesso: 04 jan. 2020.

Ribeiro, H. F., Faria, K. M. S., Cezare, C. H. G. 2019. Dinâmica espaço-temporal do desmatamento nos territórios da cidadania no nordeste goiano. Revista Brasileira de Geografia Física, v.12, 1180-1196. 
Disponível:http://www.revistas.usp.br/rdg/artic le/view/47288. Acesso: 04 jan. 2020. https://periodicos.ufpe.br/revistas/rbgfe/article/ view/238875. Acesso: 04 jan. 2020.

Rosa, R. 2005. Geotecnologias na Geografia aplicada. Revista do Departamento de Geografia, 16, 81-90. Disponível: http://www.revistas.usp.br/rdg/article/view/472 88. Acesso: 04 jan. 2020.

Rodrigues, B.M., B.M., Osco, L.P., Antunes, P.A., Ramos, A.P.M. 2019. Avaliação da influência do uso e cobertura da terra na qualidade das águas superficiais da bacia hidrográfica do rio Pirapozinho (SP). Revista Brasileira de Geografia Física, 12, 738-753. Disponível: https://periodicos.ufpe.br/revistas/rbgfe/article/ view/237355. Acesso: 04 jan. 2020.

Santos, F.A.A., Rocha, E.J.P., Santos, J.S. 2019. Dinâmica da Paisagem e seus Impactos Ambientais na Amazônia. Revista Brasileira de Geografia Física, 12, 1794-1815. Disponível:https://periodicos.ufpe.br/revistas/r bgfe/article/view/238378. Acesso: 04 jan. 2020.

Silva, D.G., Arruda, I. R. P., Silva, M. L. G., Ferreira, P. S., Gomes, V. P. 2016. Análise espaço-temporal do uso e cobertura da terra no município de Exu, PE. Clio Arqueológica, 31, 193-210. Disponível: https://www.researchgate.net/publication/3164 46148_ANALISE_ESPACOTEMPORAL_DO_USO_E_COBERTURA_D A_TERRA_NO_MUNICIPIO_DE_EXU__PE. Acesso: 04 jan. 2020.

Silva, J.R.; Lustosa, G.S.; Veras-dos-Santos, D.S. 2016. Análise dos estudos ambientais realizados em Caxias - MA nos anos 2010 a 2014. Cadernos Cajuína, v.1, n.2, 2016, p.100-118. Disponível em:< https://cadernoscajuina.pro.br/revistas/inde x.php/cadcajuina/article/view/28/31> Acesso em: 13 de mar. de 2020.

Silva, J. X. 1992. Geoprocessamento e Análise Ambiental. Revista Brasileira de Geografia, 54, 47-61. Disponível: https://biblioteca.ibge.gov.br/visualizacao/peri odicos/115/rbg_1992_v54_n3.pdf. Acesso: 03 mar. 2020.

Tamasauskas, P.F.L.F., Tamasauskas, C.E.P. 2016. Mudanças de uso e cobertura da terra e escoamento superficial na Bacia Hidrográfica do Rio Caripi-PA: uma análise a partir das geotecnologias. Revista GeoAmazônia, 04, 153-173.

Disponível:http://www.geoamazonia.net/index. php/revista/article/download/117/pdf_88. Acesso: 04 jan. 2020.

USGS. United States Geological Survey., 2000. Using the USGS Landsat 5 Product. Disponível:https://earthexplorer.usgs.gov/. Acesso em: 07 nov. 2017.

USGS. United States Geological Survey., 2017. Using the USGS Landsat 8 Product. Disponível:https://earthexplorer.usgs.gov/. Acesso: 06 nov. 2017.

Zhu, Z.; Zhou, Y.; Seto, K.C.; Stokes, E.C.; Deng, C.; Pickett, S.T.A.; Taubenböck, H. 2019. Understanding an urbanizing planet: Strategic directions for remote sensing. Remote Sensing of Environment, 228, 164-182. Disponível em:https://www.sciencedirect.com/science/arti cle/abs/pii/S0034425719301658?via\%3Dihub. Acesso: 21 abr. 2021. 